borehole logs: implications for managed aquifer recharge. J. Hydrogeol., 2016, 24, 35-57.

5. Gleeson, T., Novakowski, K. and Kurt Kyser, T., Extremely rapid and localized recharge to fractured rock aquifer. J. Hydrol., 2009, 376(3), 496-509.

6. Dewandel, B., Lachassagne, P., Wyns, R., Marechal, J. C. and Krishnamurthy, N. S., A generalized 3D geological and hydrogeological conceptual model of granite aquifers controlled by single or multiphase weathering. J. Hydrol., 2006, 330, 260-284.

7. Dewandel, B. et al., Development of a tool for managing groundwater resources in semi-arid hard rock regions: application to a rural watershed in South India. Hydrol. Process., 2010, 24, 2784 2797.

8. Maréchal, J. C., Dewandel, B. and Subrahmanyam, K., Characterization of fracture properties in hard rock aquifer system. In Groundwater (ed. Thangarajan, M.), Springer, Dordrecht, The Netherlands, 2007, pp. 156-188.

9. Rushton, K. R. and Weller, J., Response to pumping of a weathered-fractured granite aquifer. J. Hydrol., 1980, 80, 299-309.

10. Rushton, K. R., Vertical flow in heavily exploited hard rock and alluvial aquifers. Ground Water, 1986, 24, 601-608.

11. Barker, J. A., A generalized radial flow model for hydraulic tests in fractured rock. Water Resour. Res., 1988, 24, 1796-1804.

12. Kukkillaya, J. P., Padmanabhan, K. and Krishnana, E., Use and limitations of short and medium term duration pumping tests in understanding hard rock fracture aquifers - an example from Kerala. J. Geol. Soc. India, 1999, 54, 267-277.

13. Ballukraya, P. N. and Sakthivadivel, R., Analysis and interpretation of electrical resistivity data from hard rock areas for groundwater exploration. Technical Report No. 33, Central Board of Irrigation and Power, New Delhi, 1984.

14. Ballukraya, P. N., Groundwater over-exploitation: a case study from Moje-Anepura, Kolar district, Karnataka. J. Geol. Soc., India, 1997, 50, 277-282.

15. Ballukraya, P. N., Over-exploitation and pollution of groundwater, a case study from Rasipuram area, Tamil Nadu. J. Geol. Soc., India, 2000, 56, 139-150.

16. Van Tonder, G. F., Botha, J. F., Chiang, W.-H., Kuntsman, H. and $\mathrm{Xu}, \mathrm{Y}$., Estimation of sustainable yields of borewells in fractured rock formations. J. Hydrol., 2001, 241, 79-90.

17. Van Tonder, G. F. et al., Manual on pumping test analysis in fractured rock aquifers. WRC Report No. 1116/1/02, 2002, ISBN $186845861 X$.

18. Srinivasan, V., Thomas, B. and Lilee, S., Socio-hydrology of the TG Halli catchment in India - from common property to open access. In AGU Fall Meeting abstr., 2014.

ACKNOWLEDGEMENTS. We thank IDRC, Canada and the Ministry of Earth Sciences, Government of India for providing financial assistance under the Newton-Bhabha Fund through the 'Upscaling catchment processes for sustainable water management in peninsular India' project. We also thank research staff of ATREE and University of Madras for help in carrying out while field surveys as well as borehole camera scanning, and the large number of farmers in the area for their cooperation.

Received 10 December 2018; revised accepted 8 May 2019

doi: $10.18520 / \mathrm{cs} / \mathrm{v} 117 / \mathrm{i} 1 / 130-138$

\section{A simple push-pull strategy to harvest earthworms from coconut leaf vermicompost produced in tanks}

\author{
Murali Gopal* and Alka Gupta \\ Division of Crop Production, ICAR-Central Plantation Crops Research \\ Institute, Kasaragod 671 124, India
}

The process to recycle lignin-rich coconut leaves, produced in abundance from coconut gardens, to vermicompost, using a local isolate of Eudrilus sp. is an important value-addition technology from ICARCentral Plantation Crops Research Institute helping coconut farmers and entrepreneurs to enhance their economic returns. Vermicompost is produced in cement tanks and at the end of the composting period, earthworms are hand-sorted from the mature and partially composted materials by employed workers. The scarcity of labour for earthworm sorting and nonavailability of earthworms at the required time for further vermicomposting had become an impediment in sustained production of vermicompost leading to abandonment of the technology by many adopters. To overcome this situation, a simple push-pull/pull-pull strategy was developed for harvesting the earthworms, wherein freshly ground mustard solution was used as repellant (push agent) and cow dung (with or without bagasse/banana wastes) was used as an attractant ('pull' agent). The strategy is simple, efficient and saves on labour, eliminates drudgery, reduces production cost and time. It will pave way for sustained adoption of vermicomposting technology by coconut farmers and entrepreneurs.

Keywords: Coconut leaf vermicompost, cow dung, earthworm harvesting, mustard solution, push-pull strategy.

ON average, about 6-8 tonnes of leaf biomass residues are generated from one hectare coconut (Cocos nucifera L.) garden each year. With close to 2 million ha under this plantation crop in India, many million tonnes of organic manure can be produced from this lignin-rich residue through the vermicomposting technology developed at ICAR-Central Plantation Crops Research Institute $(\mathrm{CPCRI})^{1,2}$. The technology is implemented in tanks in batches by mixing coconut leaves with cow dung (10:1 or $10: 2$ ratio, w/w basis), followed by pre-decomposition for 3-4 weeks; the coconut leaf-degrading Eudrilus sp. are then introduced in the tanks at an average of one adult worm per $\mathrm{kg}$ of feed material. The earthworms digest the substrate to convert it to vermicompost in 7590 days period. The composted material is heaped in the centre of the tanks and watering is stopped to allow the earthworms to migrate to the bottom of the heap where some moisture is available. The compost from top

*For correspondence. (e-mail: mgcpcri@yahoo.co.in) 
of the heap is separated from the partially decomposed materials (usually the mid-rib and petiole portions). Then employing labour, earthworms present at the bottom of the heap are hand-sorted (Figure 1). To harvest the earthworms from $1000 \mathrm{~kg}$ mature compost, two persons need to work for at least 7-10 days for sorting them. This need for labour had become a challenge in coconut cultivation involving organic practices in South India ${ }^{3}$ often leading to abandonment of the coconut leaf vermicomposting technology by many of the coconut farmers because of inability to timely harvest earthworms for use in the next cycle of composting.

Based on a body of work available on collection of earthworms from soils using chemical expellants ${ }^{4,5}$, drenching of the heaped coconut leaf vermicompost with mustard (Brassica juncea L.) solution, as well as formaldehyde, was tried many times but none of the worms present in the heap emerged on the surface for collection. The ineffectiveness could have been because of two reasons: quick dissipation of volatiles from the porous coconut leaf vermicompost heaps or insufficient quantity of expellant applied. Increasing the amount of expellant was found economically nonviable.

To overcome this issue and enable farmers and entrepreneurs to carry out coconut leaf vermicomposting in a sustainable manner, a simple method based on the pushpull concept was attempted to harvest the earthworms from vermicomposting sites. The push-pull strategy was first introduced in Australia to trap Helicoverpa spp. in cotton by employing an insect repelling and attractant agents $^{6}$. Later it was adopted by Rothamsted Research, UK as a business strategy for insect management based on chemical ecology principle ${ }^{7}$. This strategy was extended to coconut leaf vermicomposting technology to harvest earthworms from vermicompost heaps, by employing integrated use of volatiles released by biological materials such as mustard solution and cow dung as forces of repulsion and attraction respectively. In addition, a more simplified pull-pull approach was also found successful.

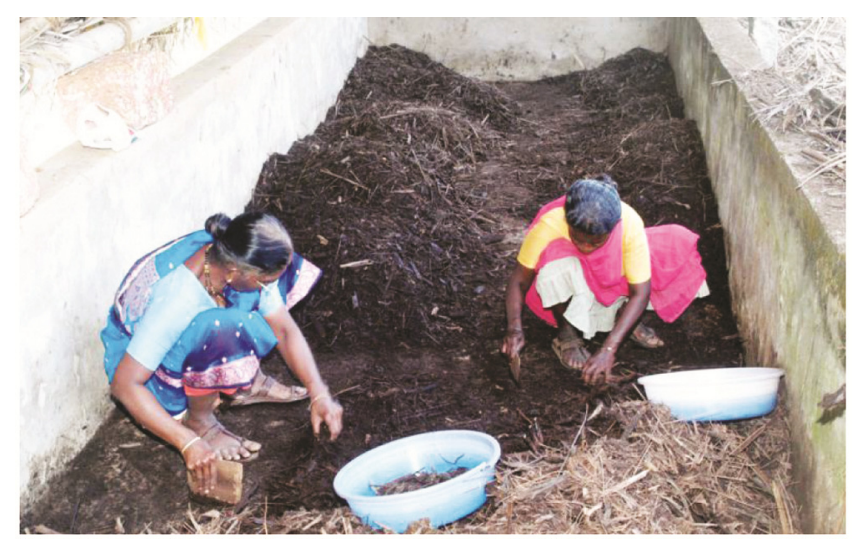

Figure 1. Harvesting of earthworms from coconut leaf vermicompost heap by hand-sorting.
This strategy also incorporates the concept of attracting hungry Eisenia fetida from vermicomposts using a mixture of food baits ${ }^{8}$.

A coconut leaf vermicompost production unit [comprising 16 large, cement tanks $(7.5 \mathrm{~m} \times 2.25 \mathrm{~m} \times 1 \mathrm{~m}$ dimensions $-16.88 \mathrm{~m}^{3}$ volume) and 4 small, brick and mortar tanks $(9 \mathrm{~m} \times 1.25 \mathrm{~m} \times 0.75 \mathrm{~m}$ dimensions $8.44 \mathrm{~m}^{3}$ volume)] and an Eudrilus sp. earthworm multiplication unit are available at CPCRI. About 20-25 tonnes of coconut leaf vermicompost is produced in batches each year. Earthworms are supplied/sold to farmers and entrepreneurs as citizen service 9 . As CPCRI carries out extensive studies on composting strategies, experiments were set up at coconut leaf vermicomposting sites with different organic materials for simple and easy extraction of earthworms to reduce labour/drudgery and cost dependence. The earthworm harvesting by push-pull strategy was attempted from August 2016 to June 2017 in different batches.

A preliminary trial was carried out in plastic basins to assess the potential of the push-pull strategy to harvest the earthworms (Figure $2 a-d$ ). For this, about $2 \mathrm{~kg}$ predecomposed coconut leaves were taken in a plastic basin (50 cm dia and $15 \mathrm{~cm}$ depth) and 10 adult earthworms were introduced. At the centre of the substrate, a small circular space was made and $25 \mathrm{~g}$ of mustard solution was poured and the basin covered with a cardboard sheet to prevent the entry of light. After 10-15 $\mathrm{min}$, the basin was observed for any reaction from the earthworms. However, none were seen emerging from the edges of the substrate into the open to escape the volatiles from mustard solution. Nonetheless, when the substrate was carefully perused, all the earthworms were found at the periphery of the substrate confirming the repellant action of the mustard. As a next step, a layer of cow dung slurry was spread around the periphery of the substrate and the basin was observed again after $10 \mathrm{~min} ; 7$ to 8 out of 10 earthworms were found in the cow dung patch. All the 10 worms were found to move to the cow dung patch within $30 \mathrm{~min}$. Further, to ensure the repellant action from mustard solution, cow dung slurry along the periphery was replaced with plain soil and coir-pith compost in the basin trials. In all the cases, earthworms migrated away from the centre of the basin, where the mustard solution was poured, to the periphery, where soil/coir-pith compost was placed. The above experiments were repeated at least three times before taking up large-scale push-pull trial.

The large-scale trial was carried out in the ready-toharvest coconut leaf vermicomposting posting tanks and push-pull strategy was adopted to manipulate earthworms' migration from the vermicomposted heap to the adjacently laid fresh cow dung from where they were eventually collected, thus making sorting of earthworms from vermicomposting tanks easy and labourfriendly. 


\section{RESEARCH COMMUNICATIONS}

Three small, brick and mortar tanks (A, B and D) were chosen for the earthworm extraction experiments. Each tank ( $9 \mathrm{~m} \times 1.25 \mathrm{~m} \times 0.75 \mathrm{~m}$ dimensions) had three compartments of approximately $3 \mathrm{~m}$ in length. Each compartment was filled with $450 \mathrm{~kg}$ of coconut leaves and $50-60 \mathrm{~kg}$ of cow dung slurry and 500 earthworms. Tanks were regularly watered to keep the moisture content at 40-50\%. The earthworms converted the coconut leaf-cow dung mixture to vermicompost in 75-90 days period. The drop in the level of substrate to half the tanks' depth was considered as a visual indicator for completion of the vermicomposting. At this stage, in place of the usual practice of heaping the compost in the centre of tanks and hand sorting, the push-pull strategy was adopted.

The compost material was heaped like a windrow within the tank. Sufficient free area on both sides along the length of the heap was left. PVC pipes $(70 \mathrm{~cm}$ length and $8 \mathrm{~cm}$ diameter) were inserted into the middle of the heap such a way that the bottom reached the maximum depth of the heap. Fresh mustard solution (about $250 \mathrm{~g}$ mustard paste in one litre of water) was added into the tubes such that the solution reaches the centre of the heap. A thin strip of cow dung slurry (5-6 kg cow dung mixed with 121 of water) was spread on the periphery of the vermicomposting heap (Figure 3). A proper moistening of the compost edges was done by sprinkling water from a rose can along the entire length of the heap. The cow dung slurry and mustard solution were applied in the evening hours. After every $24 \mathrm{~h}$, the cow dung strip was slightly disturbed to check for the presence of earthworms. Once a good population was seen, the cow dung along with the earthworms was collected using a wooden scraping board. The number of adult and juvenile worms was then
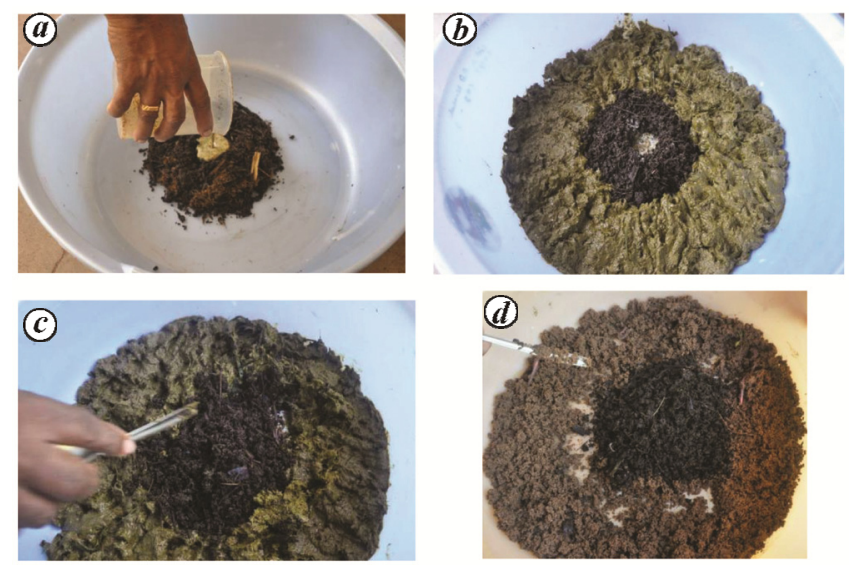

Figure 2. Push-pull trial in small plastic basins. $\boldsymbol{a}$, Push trial by applying mustard solution (push agent) to vermicompost containing earthworms. The earthworms did not emerge from the compost heap and remained accumulated at the outer edge of the compost. $\boldsymbol{b}, \boldsymbol{c}$, Putting a patch of cow dung (pull agent) around the vermicompost and application of mustard solution (push agent) caused a quick migration of the earthworms away from mustard into the cow dung patch. $\boldsymbol{d}$, Earthworms migrated to coir-pith compost and soil cover placed around compost confirming the push effect of mustard paste. counted. Weight of 100 adult worms was also measured. A second round of cow dung slurry application was done, the earthworms harvested and counted. After two harvests using this push-pull strategy, the remaining earthworms in the vermicompost heap were hand-sorted and counted. This trial was carried out in three separate compartments of the vermicomposting tank representing three replications. Three vermicomposting tanks were used for this experiment.

In the second trial, cow dung + sugar cane bagasse $(1: 1, \mathrm{w} / \mathrm{w})$, cow dung + partially dried banana pseudostem and leaves $(1: 1, \mathrm{w} / \mathrm{w})$ and cow dung + coir-pith compost $(1: 1, \mathrm{w} / \mathrm{w})$ were used as mixed attractants for the earthworms. Mustard solution remained as the repelling agent. This was carried out in the large, cement vermicomposting tanks $(7.5 \mathrm{~m} \times 2.25 \mathrm{~m} \times 1.0 \mathrm{~m}$ dimensions). One tank each was used for each type of the attractant mixture. Here too, mustard solution was applied only once, whereas the attractants were applied twice.

A third trial was carried out in small, brick and mortar vermicomposting tanks $(9 \mathrm{~m} \times 1.25 \mathrm{~m} \times 0.75 \mathrm{~m})$ wherein application of mustard solution, the 'push' component, was avoided and only mixture of 'pull' components (cow dung with other attractants) was used and the harvesting efficiency of the earthworms was evaluated. A combination of cow dung + banana wastes, cow dung + sugarcane bagasse and cow dung + coir-pith compost was applied to single compartments of the tanks and the earthworm harvest was recorded. Because two organic materials were used as an attractant mix, we termed it as pull-pull strategy. In one compartment, cow dung alone was applied. The ratio of cow dung to other organic material was kept at $1: 1(\mathrm{w} / \mathrm{w})$ as that of the trials done in large, cement tanks.

The pre-trial in small plastic basins clearly indicated the ability of mustard solution to repel the earthworms. In the first attempt, where only the mustard solution was added to the substrate, the worms were not seen emerging out of the substrate because of their behaviour of not venturing out in open spaces even though the basin was covered with opaque card board to prevent light entry into the basins. However, an addition of a layer of cow dung patch around the substrate allowed the worms to move as far away as possible from the centre of the basins where mustard solution was added. Use of different organic materials such as soil or coir-pith compost as cover patch around the substrate allowed the earthworms to migrate away from the mustard solution. The time taken by the earthworms to move away from the repellent to the attractant material was quickest in cow dung. It took 20 $30 \mathrm{~min}$ for all the 10 adult earthworms to move to the cow dung patch. With soil and coir-pith compost, it took between 25 and $45 \mathrm{~min}$ for all the earthworms to migrate into the attractant portion. The volatile, allyl isothiocyanate, released from mustard solution is a known earthworm irritant which acts as a repellant/expellant ${ }^{5}$. The 


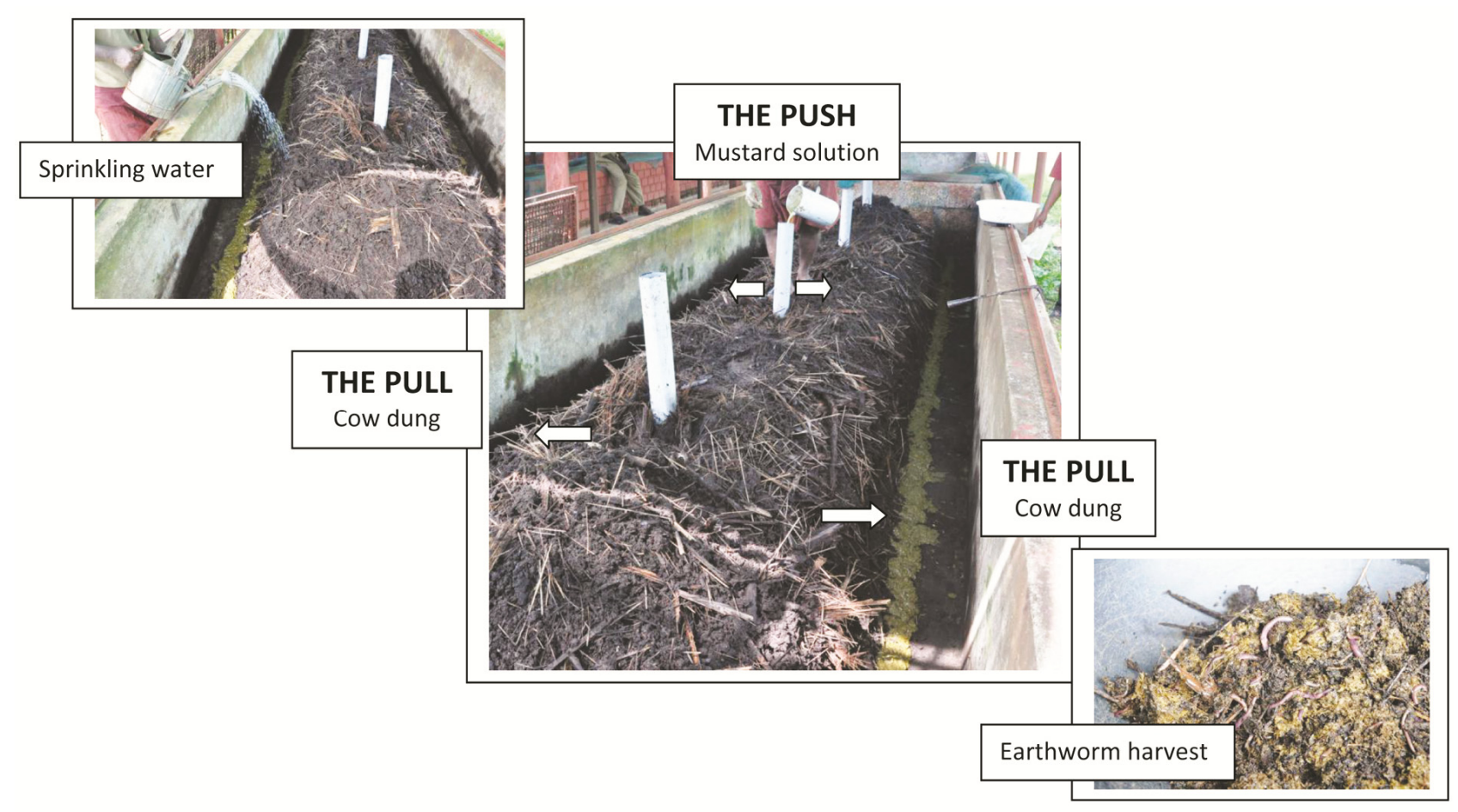

Figure 3. Push-pull strategy of harvesting earthworms from windrow-style heaped coconut leaf vermicompost produced in large tanks. Sprinkling water along the edges of compost heap helps in better attraction of the earthworms from inside the pile. A large number of adult earthworms can be easily harvested by this push-pull strategy.

attractant volatile cues from cow dung are still unknown and require basic chemical ecology studies. However, it is well established that cow dung is one of the favoured food for the earthworm and certainly some positive olfactory signals attract the earthworms to the cow dung. It had been reported that E. fetida was attracted to volatiles such as ethyl pentanoate and ethyl hexanoate produced from the fungus Geotrichum candidum, which often was the food for this earthworm in soil ${ }^{10}$. Analysis of the volatiles present in cow manure (dung) revealed that out of 44 volatile organic compounds, 3-methyl-dodecane, 1methyl naphthalene and 3-methyl-1H-indole were dominant ${ }^{11}$. In yet another study of volatile profiling of dairy manure, about 86 odorants mainly belonging to sulphur, fatty acids, ketones, esters and phenol/indole derivatives were identified $^{12}$.

Based on pre-trial observations in plastic basins, the push-pull strategy of earthworm harvesting was applied to coconut leaf vermicomposting carried out on a larger scale in brick and mortar tanks. Counting of the earthworms from the scooped cow dung patch clearly indicated that more than $85 \%$ of the adults could be harvested by one-time application of mustard solution as push agent and two-time application of cow dung as pull agent (Table 1). The cow dung patch was lifted from approximately $500 \mathrm{~kg}$ of compost heap containing more than $50-60 \%$ mature compost and the rest partially decomposed petiole and slender stick-like midrib of the coconut leaves. About 15-16\% earthworms remained in the compost heap still feeding on the partially composted substrates. The data also indicated that there was a doubling of the number of the earthworms added to the substrate, i.e. 500 worms inoculated initially multiplied and increased to more than 1000 worms in the given period of vermicomposting. About $20 \%$ juveniles too could be harvested by the push-pull method (Table 1). The multiplication rate of Eudrilus sp. in the coconut leaf + cow dung substrate is influenced by several factors: temperature and humidity being the critical ones. When the conditions are optimum, close to five times multiplication of earthworms could be achieved; and if the conditions are not suitable, the final count can become less than the inoculated numbers ${ }^{13}$. In the push-pull trial, an in-between count was obtained which could have been due to unusual hot weather and less frequency of precipitation experienced when the trials were carried out.

In the second large-scale push-pull trial carried out in cement tanks using single or a mixture of attractants, we could harvest $80-86 \%$ of the adult earthworms from $1000 \mathrm{~kg}$ compost heap (Table 2). About $14-20 \%$ of adult earthworms remained in the compost heap after two rounds of harvesting. This might be due to higher substrate volume accommodated in the large, cement tanks, offering more partially decomposed food material compared to the smaller, brick and mortar tanks; and also, partially due to the inability of the volatiles from 


\section{RESEARCH COMMUNICATIONS}

Table 1. Eudrilus sp. earthworms harvested from small, brick and mortar coconut leaf vermicomposting tanks $(9 \mathrm{~m} \times 1.25 \mathrm{~m} \times 0.75 \mathrm{~m}) *$ adopting push-pull strategy using mustard solution-cow dung application**

\begin{tabular}{|c|c|c|c|c|c|c|c|c|c|c|c|c|}
\hline \multirow[b]{2}{*}{ Details of earthworms harvested } & \multicolumn{4}{|c|}{ Tank A } & \multicolumn{4}{|c|}{ Tank B } & \multicolumn{4}{|c|}{ Tank D } \\
\hline & A1 & A2 & A3 & Mean & $\mathrm{B} 1$ & $\mathrm{~B} 2$ & B3 & Mean & D1 & D2 & D3 & Mean \\
\hline Earthworms remaining in mature compost & 138 & 143 & 140 & 140 & 128 & 141 & 142 & 137 & 140 & 130 & 148 & 139 \\
\hline Total no. of adult worms & 1138 & 1148 & 1120 & 1135 & 1138 & 1085 & 1050 & 1096 & 1093 & 1037 & 1082 & 1070 \\
\hline$\%$ adult worms harvested by push-pull & $88 \%$ & $87 \%$ & $88 \%$ & $88 \%$ & $89 \%$ & $87 \%$ & $86 \%$ & $87 \%$ & $87 \%$ & $86 \%$ & $86 \%$ & $86 \%$ \\
\hline
\end{tabular}

*Each small brick and mortar vermicomposting tank ( $A, B$ and $D)$ was separated into three equal compartments $\left(A_{1}, A_{2}, A_{3} ; B_{1}, B_{2}, B_{3} ; D_{1}, D_{2}, D_{3}\right)$. Each compartment of the tanks was filled with $450 \mathrm{~kg}$ of coconut leaves and drenched with $50-60 \mathrm{~kg}$ of cow-dung slurry and constantly kept moist with regular watering for pre-decomposition until 15-20 days. Inoculation of 500 adult Eudrilus sp. earthworms was carried out after predecomposition period. Harvesting of the earthworms was carried out after 75-90 days period when the substrate level dropped to half the tank height.

**Mustard solution was a 'push' and cow dung was a 'pull' agent.

Table 2. Eudrilus sp. earthworms harvested from large, cement coconut leaf vermicomposting tanks $(7.5 \mathrm{~m} \times 2.25 \mathrm{~m} \times 1.0 \mathrm{~m}) *$ adopting pushpull strategy with mustard solution as a repellant and a mixture of attractants**

\begin{tabular}{|c|c|c|c|c|}
\hline \multirow[b]{2}{*}{ Details of earthworms harvested } & \multicolumn{4}{|c|}{ Repellant-attractants used } \\
\hline & $\begin{array}{l}\text { Mustard- } \\
\text { cow dung }\end{array}$ & $\begin{array}{l}\text { Mustard-cow dung } \\
\text { amended with banana } \\
\text { pseudo-stem and leaves }\end{array}$ & $\begin{array}{c}\text { Mustard- } \\
\text { cow dung amended } \\
\text { with sugarcane bagasse }\end{array}$ & $\begin{array}{c}\text { Mustard- } \\
\text { cow dung amended } \\
\text { with coir-pith compost }\end{array}$ \\
\hline Adult earthworms harvested by push-pull & 1740 & 2050 & 1990 & 1780 \\
\hline Earthworms remaining in mature compost & 450 & 320 & 350 & 410 \\
\hline$\%$ adult earthworms harvested by push-pull & $80 \%$ & $86 \%$ & $85 \%$ & $81 \%$ \\
\hline Juvenile earthworms harvested by push-pull & 290 & 250 & 265 & 270 \\
\hline
\end{tabular}

*Each large tank was filled with $900-950 \mathrm{~kg}$ of coconut leaves and drenched with $100-125 \mathrm{~kg}$ of cow-dung slurry and constantly kept moist with regular watering for pre-decomposition until 15-20 days. Inoculation of 1000 adult Eudrilus sp. earthworms was carried out after predecomposition period. Harvesting of the earthworms was carried out after 75-90 days period when the substrate level dropped to half the tank height.

**Results represent data from one separate large tank per experiment.

both push and pull component to reach deeper parts of the compost heap. However, a harvest of above $80 \%$ was considered on par in terms of the benefits it accrued.

An attempt was made to study the earthworm harvest efficacy by avoiding the push component, for which a pull-pull trial was conducted in the smaller, brick and mortar tanks with different sets of attractants applied as bait to the earthworms. A separate single compartment of the small, brick and mortar vermicomposting tank was used for each type of attractant. Here too, close to $80 \%$ of adult earthworms could be harvested from $500 \mathrm{~kg}$ compost material (Table 3 ). These results reflected the experience drawn from an earlier study that mixing sugarcane bagasse or banana pseudo-stem with coconut leaves was preferred by this Eudrilus sp. for vermicompost production $^{14}$. Even the application of cow dung alone was able to extract $76 \%$ of the worms from the coconut leaf vermicompost. The use of single food bait such as cow dung or multiple food baits such as cow dung + valerian (Valeriana officianalis) or cow dung + nettle (Urtica dioica) or cow dung + flax seed had been reported to extract the earthworm $E$. fetida introduced into vermicompost filled in 601 pots $^{8}$. Unlike Kostecka and $\mathrm{Garg}^{8}$ where preprepared vermicompost (produced entirely from cow dung substrate) was filled into pots and the earthworms added for the extraction experiment, our studies were conducted in large cement tanks in the on-going process of well-established coconut leaf vermicompost production system. Here, the earthworms were inoculated into the pre-decomposed substrate of coconut leaves + cow dung slurry $(10: 1, \mathrm{w} / \mathrm{w})$ and allowed to convert the substrate to vermicompost and at the finishing stage, they were extracted using either push-pull or pull-pull strategy.

The advantage of using the mixed attractants was that it helped in reducing the quantity of cow dung requirement to half. The sugarcane bagasse and banana pseudostem/leaves are available as unutilized agro-wastes in many of the states where coconut is grown in India. This could help in reducing the expenditure on cow dung in case the farmer or entrepreneur does not own cattle. The ability of cow dung, sugarcane bagasse and banana 


\section{RESEARCH COMMUNICATIONS}

Table 3. Eudrilus sp. earthworms harvested from small, brick and mortar coconut leaf vermicomposting tanks $(9 \mathrm{~m} \times 1.25 \mathrm{~m} \times 0.75 \mathrm{~m}) *$ adopting pull-pull strategy with a mixture of attractants**

\begin{tabular}{|c|c|c|c|c|}
\hline \multirow[b]{2}{*}{ Details of earthworms harvested } & \multicolumn{4}{|c|}{ Attractant(s) used } \\
\hline & Cow dung alone & $\begin{array}{c}\text { Cow dung } \\
\text { amended with banana } \\
\text { pseudostem and leaves }\end{array}$ & $\begin{array}{c}\text { Cow dung } \\
\text { amended with } \\
\text { sugarcane bagasse }\end{array}$ & $\begin{array}{c}\text { Cow dung } \\
\text { amended with } \\
\text { coir-pith compost }\end{array}$ \\
\hline Adult earthworms harvested by pull-pull & 850 & 900 & 910 & 845 \\
\hline Earthworms remaining in mature compost & 260 & 200 & 210 & 225 \\
\hline$\%$ adult earthworms harvested by pull-pull & $76 \%$ & $81 \%$ & $81 \%$ & $78 \%$ \\
\hline Juvenile earthworms harvested by pull-pull & 125 & 140 & 120 & 130 \\
\hline
\end{tabular}

*Each compartment of the tank was filled with $450 \mathrm{~kg}$ of coconut leaves and drenched with $50-60 \mathrm{~kg}$ of cow-dung slurry and constantly kept moist with regular watering for pre-decomposition until 15-20 days. Inoculation of 500 adult Eudrilus sp. earthworms was carried out after predecomposition period. Harvesting of the earthworms was carried out after 75-90 days period when the substrate level dropped to half the tank height.

**Results represent data from experiment carried out in a separate single compartment of small tank.

Table 4. Number of days taken to harvest the adult earthworms from small, brick and mortar vermicomposting tanks with two rounds of repellant-attractant application

\begin{tabular}{lc}
$\begin{array}{l}\text { Push-pull/pull-pull } \\
\text { components }\end{array}$ & $\begin{array}{c}\text { Days taken for harvesting } \\
\text { earthworms from small, } \\
\text { brick and mortar tanks* }\end{array}$ \\
\hline Mustard-cow dung & 08 \\
Cow dung + banana pseudostem and leaves & 10 \\
Cow dung + sugarcane bagasse & 10 \\
Cow dung + coir pith compost & 11 \\
Cow dung alone & 12 \\
\hline
\end{tabular}

*Dimensions $-(9 \mathrm{~m} \times 1.25 \mathrm{~m} \times 0.75 \mathrm{~m})$.

Table 5. Number of days taken to harvest the adult earthworms from large, cement vermicomposting tanks with two rounds of repellantattractant application

\section{Push-pull/pull-pull components}

Mustard-cow dung

Mustard-cow dung + banana pseudostem and leaves

Mustard-cow dung + sugarcane bagasse

Mustard-cow dung + coir pith compost

*Dimensions $(7.5 \mathrm{~m} \times 2.25 \mathrm{~m} \times 1.0 \mathrm{~m})$.

pseudo-stem/leaves to attract earthworms was also aided by water sprinkling along the vermicompost-attractant interface. This was done because, as the compost heap started drying out from the edges, the earthworms moved towards the inner area of higher moisture availability. Thus, re-wetting facilitated returning of the earthworms to the moistened edges of the vermicompost heap. The volatiles from attractants then hastened their migration from the inner areas of vermicompost pile. The migration of earthworms to cow dung + mixed attractant patch could easily be noticed by the presence of fresh granular vermicasts. The vermicast volume increased over time with more adult earthworm migration and it slowly became visible at the outermost edge of the attractant patch. At this stage, the whole patch could be scooped for earthworm harvest. The other simple way to ascertain the presence of earthworms in the patch was by disturbing the cow dung and looking for the worms as mentioned earlier. The push-pull as well as pull-pull approach was able to attract adult earthworms with weights that ranged from 83 to $107 \mathrm{~g}$ per 100 worms. The earthworm biomass reported in our experiment was on par or marginally lesser than the individual body weights ( 1.0 to $1.2 \mathrm{~g})$ of $E$. eugeniae when grown on different crop residues and cattle shed manure ${ }^{15}$. However, it was higher than the E. eugeniae weights recorded in 14 different locations in Laos, Nigeria ${ }^{16}$.

The time taken for harvesting of adult earthworms in smaller brick and mortar tanks was comparatively less than the larger cement tanks (Tables 4 and 5) owing to the difference in the volume of the composts, about $7.56 \mathrm{~m}^{3}$ in the former and $16.87 \mathrm{~m}^{3}$ in the latter. The combination of push-pull and pull-pull chemistry also influenced the time period.

The biggest advantage of this push-pull/pull-pull strategy was the reduction in labour needed for harvesting the earthworms from vermicompost heaps. As mentioned earlier, to extract all the adult earthworms by hand sorting from $1000 \mathrm{~kg}$ compost, services of two persons were required for 5-7 days; equivalent to 10-14 person days. Whereas in push-pull/pull-pull method, about two hours were required for heaping the compost into a windrow, 15-30 min for application of the push and pull components and less than 15 min required for scooping the cow dung patch with the baited earthworms. In other terms, it required a maximum of two person days, thus, drastically reducing the engagement of labour. This method also eliminated the drudgery faced by labourers while hand sorting the earthworms. The labour time invested for 


\section{RESEARCH COMMUNICATIONS}

harvesting the earthworms by push-pull method could be further reduced by changing the way of heaping the compost. Instead of making windrows of the mature compost, just piling it as a sloped heap was equally effective in extracting the worms by this strategy.

In case adult earthworms were urgently required while the composting was in progress, adding a handful of cow dung in a round patch on the top of the vermicomposting substrate and moistening the surrounding area of the cow dung patch easily attracted adult earthworms within $24 \mathrm{~h}$. The application of the cow dung patch must be done in evening hours as these epigeic earthworms, having nocturnal habit, moved quickly to the cow dung patch during the evening and night time. The patch could then be lifted and the adult earthworms in the patch could be used for inoculating another vermicomposting tank or could also be supplied to other needy farmer or entrepreneur. Our above-mentioned method finds resonance with that of $\mathrm{Kale}^{17}$ who reported collection of earthworm juveniles from the compost heap by placing some cow dung at the base and over the heap of the compost. Another method is to heap the vermicompost in shade and bury cricket ball sized cow dung balls in several places. Small hatchlings of earthworms from cocoons will collect in cow dung balls that can be easily harvested.

The push-pull or pull-pull strategy using mustard as push agent and cow dung alone or mixed with sugarcane bagasse or banana pseudostem/leaf as pull agent is a simple, inexpensive and labour/drudgery saving method for earthworm harvesting for the benefit of small and marginal farmers or entrepreneurs adopting vermicomposting technology. It obviates the requirement of separate earthworm multiplication unit for the large-scale vermicompost production from coconut leaves. This methodology will help in improving the adoption of vermicomposting technology that often suffers from lack of availability of earthworms at right time.

1. Prabhu, S. R., Subramanian, P., Bidappa, C. C. and Bopaiah, B. M., Prospects of improving coconut productivity through vermiculture technologies. Indian Coconut J., 1998, 29, 79-84.

2. Gopal, M., Gupta, A. and Thomas, G. V., Opportunity to sustain coconut ecosystem services through recycling of the palm leaf litter as vermicompost: Indian scenario (a technology/research note). Coconut Res. Dev., 2010, 26, 42-55.

3. Jaganthan, D., Thamban, C., Jose, C. T., Jayasekhar, S. and Anitha Kumari, P., Analysis of organic farming practices in coconut in south India. J. Plantation Crops, 2013, 41, 71-79.

4. Lawrence, A. P. and Bowers, M. A., A test of the 'hot' mustard extraction method of sampling earthworms. Soil Biol. Biochem., $2001,34,549-552$.
5. Pelosi, C., Bertrand, M., Capowiez, Y., Boizard, H. and RogerEstrade, J., Earthworm collection from agricultural fields: comparisons of selected expellants in presence/absence of hand-sorting. Eur. J. Soil Biol., 2009, 45, 176-183.

6. Pyke, B., Rice, M., Sabine, B. and Zalucki, M. P., The push-pull strategy - behavioural control of Heliothis. Aust. Cotton Grow., 1987, 7-9.

7. Cook, S. M., Khan, Z. R. and Pickett, J. A., The use of push-pull strategies in integrated pest management. Annu. Rev. Entomol., 2007, 52, 375-400.

8. Kostecka, J. and Garg, V. K., Use of various baits for extraction of earthworms from vermicompost. J. Ecol. Eng., 2015, 16, 87-92.

9. Gopal, M., Gupta, A. and Thomas, G. V., Importance of producing nucleus earthworm culture for the dissemination and popularization of coconut leaf vermicomposting technology. Indian Coconut $J ., 2009, \mathbf{5 1}, 8-12$

10. Zirbes, L. et al., Earthworms use odor cues to locate and feed on microorganisms in soil. PLoS ONE, 2011, 6(7), e21927.

11. Huang, J., He, J., Zhang, J. and Yu, Z., Identification of volatile organic compounds in manures of cow, hog and chicken by solid phase microextraction coupled with gas chromatography/mass spectrometry. Se Pu (Chinese J. Chromatography), 2007, 25, 425429.

12. Laor, Y., Koziel, J. A., Cai, L. and Ravid, U., Chemical-sensory characterization of dairy manure odor using headspace solid-phase microextraction and multidimensional gas chromatography mass spectrometry-olfactometry. J. Air Waste Mgmt. Assoc., 2008, 58(9), 1187-1197.

13. Gopal, M., Gupta, A. and Thomas, G. V., Optimum weather conditions for efficient vermicomposting of coconut leaves by Eudrilus sp. in coastal tract of Kerala. J. Plantation Crops, 2004, 32(Suppl.), 486-490.

14. Thomas, G. V., Palaniswami, C., Gopal, M. and Gupta, A., Recycling coconut leaf-agro wastes mixture using Eudrilus sp. and growth promotion properties of coconut leaf vermicompost. Int. J. Innovative Hort., 2012, 1, 113-118.

15. Suthar, S., Bioconversion of post-harvest crop residues and cattle shed manure into value-added products using earthworm Eudrilus eugeniae Kinberg. Bioresour. Technol., 2008, 32, 206-214.

16. Oboh, B. O., Akintobi, D. O. and Ejidereonwu, C., Morphometric tric studies in Eudrilus eugeniae populations from different locations in Lagos, Nigeria. Nat. Sci., 2007, 5, 16-21.

17. Kale, R., Origins and Spread of Vermicomposting in India. Focus on Sustainable Agriculture. In Vermiculture Technology. Earthworms, Organic wastes, and Environmental Management (eds Edwards, C. A., Arancon, N. Q. and Sherman, R.), CRC Press, Boca Raton, Florida, 2011, pp. 453-467.

ACKNOWLEDGEMENT. We thank S. R. Prabhu, TerraBioGen Technologies Inc, Burnaby, Canada for giving important tips to improve the harvesting of earthworms using push-pull approach. Our sincere thanks to the anonymous reviewers for the critical suggestions made to improve the article.

Received 2 July 2018; revised accepted 23 April 2019

doi: $10.18520 / \mathrm{cs} / \mathrm{v} 117 / \mathrm{i} 1 / 138-144$ 